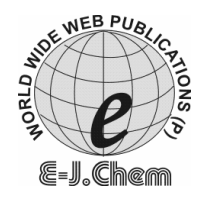

ISSN: 0973-4945; CODEN ECJHAO

E-Journal of Chemistry

http://www.e-journals.net

2009, 6(S1), S522-S528

\title{
Kinetics and Mechanism of Oxidation of Aromatic Aldehydes by Imidazolium Dichromate in Aqueous Acetic Acid Medium
}

\author{
S. SHEIK MANSOOR* and S. SYED SHAFI \\ *Department of Chemistry, C.Abdul Hakeem College, \\ Melvisharam-632 509, India. \\ Department of Chemistry, Islamiah College, \\ Vaniyambadi- 635 752, India. \\ smansoors2000@yahoo.co.in
}

Received 16 March 2009; Accepted 10 May 2009

\begin{abstract}
The kinetics of oxidation of benzaldehyde (BA) and parasubstituted benzaldehydes by imidazolium dichromate (IDC) has been studied in aqueous acetic acid medium in the presence of perchloric acid. The reaction is first order each in [IDC], [Substrate] and $\left[\mathrm{H}^{+}\right]$. The reaction rates have been determined at different temperatures and the activation parameters calculated. Electron withdrawing substituents are found to increase the reaction and electron releasing substituents are found to retard the rate of the reaction and the rate data obey the Hammett relationship. The products of the oxidation are the corresponding acids. The rate decreases with the increase in the water content of the medium. A suitable mechanism is proposed.
\end{abstract}

Keywords: Benzaldehyde, Kinetics and Mechanism, Oxidation, Imidazolium dichromate,

\section{Introduction}

A variety of compounds containing chromium(VI) have proved to be versatile reagents capable of oxidizing almost every oxidiasable functional group ${ }^{1}$. A number of new chromium(VI) containing compounds, with heterocyclic bases, like pyridinium chloro chromate $(\mathrm{PCC})^{2}$, pyridinium bromo chromate $(\mathrm{PBC})^{3-5}$, quinoliium chloro chromate $(\mathrm{QCC})^{6,7}$, quinolinium fluoro chromate $(\mathrm{QFC})^{8}$, quinolinium bromo chromate $(\mathrm{QBC})^{9}$, imidazolium fluorochromate $(\mathrm{IFC})^{10}$, pyridinium fluoro chromate $(\mathrm{PFC})^{11-14}$, imidazolium dichromate(IDC) ${ }^{15}$ and quinolinium dichromate(QDC) ${ }^{16}$ have been developed to improve the selectivity of oxidation of organic compounds. The kinetics and mechanism of oxidation of aromatic aldehydes by various oxidants have been reported ${ }^{17-19}$. However, 
the kinetics of oxidation of substituted benzaldehydes by IDC, a $\mathrm{Cr}(\mathrm{VI})$ reagent has not yet been studied. This prompted us to undertake the present investigation. The present work reports the kinetics of oxidation of para-substituted benzaldehydes by IDC and evaluates the reaction constants. Mechanistic aspects are also discussed.

\section{Experimental}

All benzaldehydes used were of AnalaR Grade (E Merck, Germany), the solid benzaldehydes were used as such and the liquid benzaldehydes were used after vacuum distillation. The oxidant imidazolium dichromate (Aldrich) was used. Acetic acid was purified by standard method and the fraction distilling at $118{ }^{\circ} \mathrm{C}$ was collected.

\section{Kinetic measurements}

The reactions were followed under pseudo-first-order conditions by maintaining a large excess ( $\times 15$ or greater) of the benzaldehyde over IDC. The temperature was kept constant to $\pm 0.1 \mathrm{~K}$. The reactions were followed by monitoring the decrease in the concentration of IDC spectrophotometrically at $363 \mathrm{~nm}$ by using Simadzu U.V /Visible spectrophotometer with recording facilities for up to $80 \%$ of the reaction. No other reactant or product has any significant absorption at this wavelength. The pseudo-first-order rate constants, $\mathrm{k}_{o b s}$, were evaluates from the linear plots of log [IDC] against time. Duplicate kinetic runs showed that the rate constants were reproducible to within $\pm 4 \%$.

\section{Product analysis}

Product study was made under mineral acid catalysed conditions in benzaldehyde. Keeping concentration of IDC in excess over benzaldehydes, the two solutions were mixed and perchloric acid was also added in 50\% acetic acid $-50 \%$ water mixtures. The reaction mixture was set aside for about $24 \mathrm{~h}$ to ensure completion of the reaction. The reaction mixture was then evaporated and extracted with ether. The ether layer was washed with water many times. The ether layer was then kept on a water bath for the evaporation of ether and cooled in ice bath to obtain the product (m.p. $121{ }^{\circ} \mathrm{C}$ ). The product was dissolved in benzene and a careful TLC analysis was done with benzoic acid and benzaldehyde as references. Only one spot corresponding to benzoic acid was obtained. Formation of benzoic acid was further confirmed by mixing the product with pure benzoic acid and noting that there was no change in the melting point.

\section{Stoichiometric studies}

Stoichiometric analysis showed that $3 \mathrm{~mol}$ of aldehyde consumed $2 \mathrm{~mol}$ of IDC in accordance with $\mathrm{Eq}(1)$ to give the corresponding carboxylic acid.

$$
3 \mathrm{ArCHO}+2 \mathrm{IDC}+\mathrm{H}^{+} \longrightarrow 3 \mathrm{ArCOOH}+2 \mathrm{Cr}(\mathrm{III})
$$

\section{Results and Discussion}

Oxidation of benzaldehyde by IDC has been conducted in 50\% acetic acid - 50\% water medium at $303 \mathrm{~K}$, under the pseudo-first-order conditions and the observed results were discussed in the following pages.

\section{Effect of varying oxidant concentration}

The concentration of IDC was varied in the range $6.00 \times 10^{-4}$ to $3.0 \times 10^{-3} \mathrm{~mol} \mathrm{dm}^{-3}$ and keeping all other reactant concentrations as constant and the rates were measured (Table 1). The near constancy in the value of $k_{1}$ irrespective of the concentration of the IDC confirms the first order dependence on IDC. 


\section{Effect of varying substrate concentration}

The substrate benzaldehyde was varied in the range of $1.00 \times 10^{-2}$ to $2.5 \times 10^{-2} \mathrm{~mol} \mathrm{dm}^{-3}$ at $303 \mathrm{~K}$ and keeping all other reactant concentrations as constant and the rates were measured (Table 1). The rate of oxidation increased progressively on increasing the concentration of benzaldehyde, indicating first order dependence with substrate. The plot of $\log \mathrm{k}_{\mathrm{obs}}$ versus $\log [\mathrm{BA}]$ gave the slope of $0.967(\mathrm{r}=0.996)$ (Figure 1) shows that this oxidation reaction was first order with respect to [BA]. The second order rate constant $k_{2}$ is invariant supporting the first order dependence on [BA].

Table 1. Effect of varying [BA], [IDC] and $\left[\mathrm{HClO}_{4}\right]$ on the rate reaction at $303 \mathrm{~K}$ $\mathrm{AcOH}-\mathrm{H}_{2} \mathrm{O}=50 \%-50 \%(\mathrm{v} / \mathrm{v})$

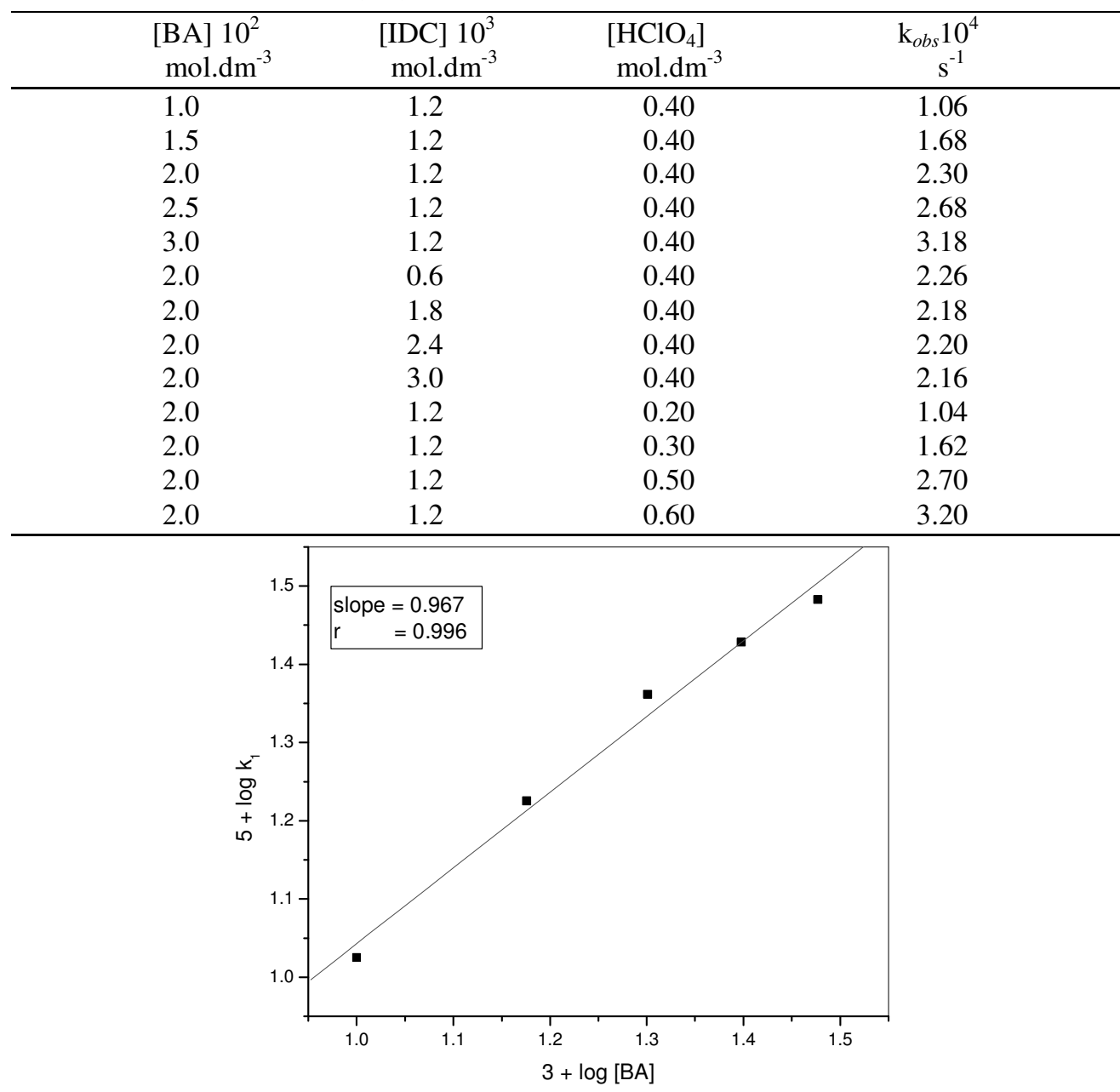

Figure 1. Variation of rate with benzaldehyde concentration.

\section{Effect of perchloric acid concentration}

The perchloric acid concentration was varied in the range of 0.2 to $0.6 \mathrm{~mol} \mathrm{dm}^{-3}$ and keeping the concentrations of all other reactant concentrations as constant and the rates were measured (Table 1). The increase in $\left[\mathrm{HClO}_{4}\right]$ in the oxidation reaction increases the 
rate of the reaction and shows a direct first order dependence on $\left[\mathrm{HClO}_{4}\right]$. A plot of $\log$ $\mathrm{k}_{1}$ against $\log \left[\mathrm{H}^{+}\right]$is linear. Change in ionic strength by the addition of $\mathrm{NaClO}_{4}$ has no effect on the rate constant. Under the acid concentrations used in the present investigations, the protonation of the aldehydes would be less significant. The possibility of the aldehydes getting protonated can be ruled out on the basis that aldehydes are extensively hydrated in an aqueous medium, and are present as equilibrium mixtures of the carbonyl and hydrated forms. The formation constants are thus not dependent on the acidity or alkalinity ${ }^{20}$. Hence, it would be justified to propose that in the range of acid concentrations used the oxidant IDC was converted to the protonated chromium(VI) species. Earlier reports have established the involvement of protonated $\mathrm{Cr}(\mathrm{VI})$ species in chromic acid oxidation reactions ${ }^{14}$.

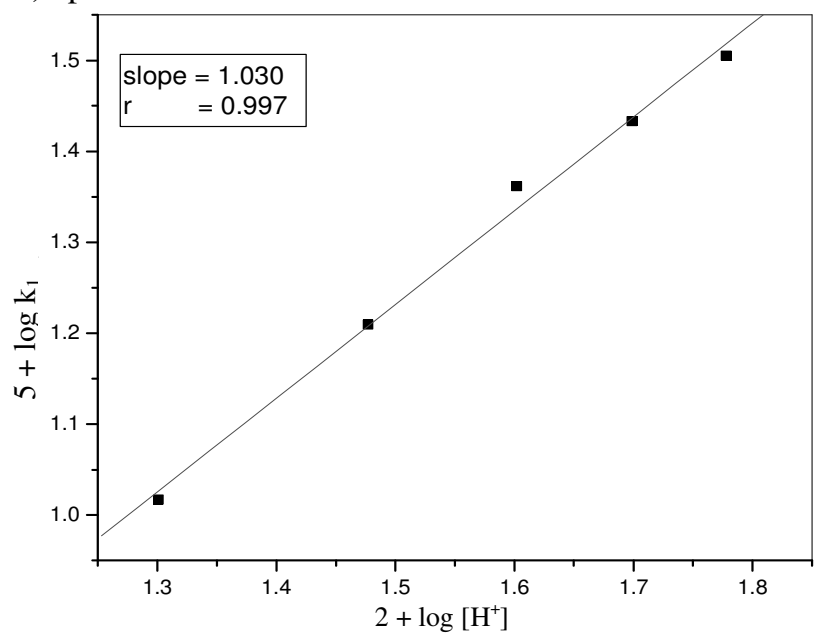

Figure 2. Effect of variation of $\left[\mathrm{H}^{+}\right]$.

\section{Effect of solvent composition}

The effect from solvent composition on the reaction rate was studied by varying the concentration of acetic acid from $30 \%$ to $70 \%$. The pseudo-first-order rate constants were estimated for the oxidation reactions of all of the substituted benzaldehydes, with IDC in the presence of prechloric acid at a constant ionic strength. The reaction rate is increases markedly with the increase in the proportion of acetic acid in the medium (Table 2). When the acetic acid content increases in the medium, the acidity of the medium is increased whereas the dielectric constant of the medium is decreased. These two effects cause the rate of the oxidation to increase markedly. The observed effect is similar to those reported for the oxidation of benzaldehyde by quinolinium dichromate ${ }^{14}$.

The enhancement of the reaction rate with an increase in the amount of acetic acid generally may be attributed to two factors, viz, (i) the increase in acidity occurring at constant $\left[\mathrm{H}^{+}\right]$and (ii) the decrease in dielectric constant with an increase in the acetic acid content ${ }^{22}$. The magnitude of this effect could be analysed by suggesting that, for the equilibrium $2 \mathrm{HCrO}_{4}^{-} \rightleftharpoons \mathrm{Cr}_{2} \mathrm{O}_{7}{ }^{2-}+\mathrm{H}_{2} \mathrm{O}$, a decrease in the dielectric constant of the medium would favour the dichromate form over the chromate form. If ion pairs were to be formed in this medium, it would be expected that they have a higher ion-pair association constant for the dichromate ion. Plots of $\log \mathrm{k}_{1}$ versus $1 / \mathrm{D}$ were found to be linear, with positive slopes, which indicated that the reaction were of the ion-dipole type ${ }^{23}$. 
Table 2. Effect of the solvent polarity on the rate of reaction at $303 \mathrm{~K}$ $[\mathrm{BA}]=2.0 \times 10^{-2} \mathrm{~mol} \mathrm{dm}^{-3},[\mathrm{IDC}]=1.2 \times 10^{-3} \mathrm{~mol} \mathrm{dm}^{-3},\left[\mathrm{HClO}_{4}\right]=0.4 \mathrm{~mol} \mathrm{dm}^{-3}$.

\begin{tabular}{lcccccc}
\hline Substrate & $10^{4} \mathrm{k}_{1}{ }^{\mathrm{a}}, \mathrm{s}^{-1}\left(\mathrm{AcOH}: \mathrm{H}_{2} \mathrm{O}(\mathrm{v} / \mathrm{v}), \%\right)$ & & & \\
& $40-60$ & $50-50$ & $60-40$ & $70-30$ & Slope $^{\mathrm{b}}$ & $\mathrm{r}^{\mathrm{b}}$ \\
\hline$p-\mathrm{OCH}_{3}$ & 0.41 & 0.58 & 0.64 & 0.92 & 31.6 & 0.982 \\
$p-\mathrm{CH}_{3}$ & 0.93 & 1.16 & 1.34 & 1.63 & 22.2 & 0.978 \\
$\mathrm{H}$ & 1.86 & 2.30 & 2.90 & 3.40 & 24.9 & 0.986 \\
$p-\mathrm{Cl}$ & 3.20 & 3.80 & 4.60 & 5.32 & 20.5 & 0.994 \\
$\mathrm{p}-\mathrm{CN}$ & 11.20 & 12.40 & 13.80 & 15.28 & 12.8 & 0.997 \\
$p-\mathrm{NO}_{2}$ & 13.50 & 15.00 & 18.00 & 20.88 & 18.2 & 0.997 \\
\hline
\end{tabular}

${ }^{a}$ Estimated from pseudo-first-order reaction plots,

${ }^{b}$ These values were calculated from the plots drawn between log $k_{l}$ and $1 / D$.

\section{Mechanism and rate law}

The sequence of reactions for the oxidation of benzaldehydes by IDC, in an acid medium is shown in Scheme1. In an acid medium, the oxidant IDC is converted to the protonated bimetallic chromium(VI) species (PIm). The protonated IDC would have the $\mathrm{Cr}(\mathrm{VI})$ existing mainly as $\mathrm{Cr}_{2} \mathrm{O}_{7}{ }^{2-}$. The substrate (BA) was converted to hydrated form (HY). The reaction of the hydrated form (HY) of the substrate with the protonated IDC (PIm) resulted in the formation of the monochromate ester ${ }^{21}$ which undergo decomposition in the rate determining step give the product.

Based on the mechanism shown in Scheme1, the rate law has been derived as follows:

$$
-\mathrm{d}[\mathrm{IDC}] / \mathrm{dt}=\mathrm{k}_{3}[\mathrm{E}]=\mathrm{k}_{3}[\mathrm{HY}][\mathrm{PIm}],
$$

Where, $[\mathrm{PIm}]=\mathrm{K}_{1}[\mathrm{IDC}]\left[\mathrm{H}^{+}\right]$, and $[\mathrm{HY}]=\mathrm{K}_{2}[\mathrm{BA}]\left[\mathrm{H}_{2} \mathrm{O}\right]$.

Substituting the values of [PIm] and [HY], the following equation was obtained:

$$
-\mathrm{d}[\mathrm{IDC}] / \mathrm{dt}=\mathrm{K}_{1} \mathrm{~K}_{2} \mathrm{k}_{3}[\mathrm{BA}][\text { IDC }]\left[\mathrm{H}_{2} \mathrm{O}\right]
$$

From this expression, it is clear that the reaction exhibited first-order dependence with respect to the concentrations of each substrate, oxidant and acid. This rate law explains all the experimentally observed results.

\section{Oxidation of some para-substituted benzaldehydes with IDC}

In order to study the effect of structure on reactivity, some para-substituted benzaldehydes were subjected to oxidation kinetics by IDC at four different temperatures viz., 298, 303, 308 and $313 \mathrm{~K}$ in $50 \%-50 \%(\mathrm{v} / \mathrm{v})$ acetic acid - water medium in presence of perchloric acid. Substrate effect reveals that para-substituted benzaldehydes also first order dependence. The second order rate constants at four different temperatures with the activation parameters are given in the Table 3. It is interesting to note that the reactivity decreases in the order $p-\mathrm{NO}_{2}$ $>p$ - $\mathrm{CN}>p$ - $\mathrm{Cl}>p-\mathrm{H}>p-\mathrm{CH}_{3}>p-\mathrm{OCH}_{3}$ for the substituents.

The Exner plot $\log \mathrm{k}_{2}(303 \mathrm{~K})$ versus $\log \mathrm{k}_{2}(313 \mathrm{~K})$ is linear (Figure $3 ; \mathrm{r}=0.996$, $\mathrm{SD}=0.031)$ and the isokinetic temperature $\beta$ obtained from the slope is $413 \mathrm{~K}$. This supports the arguments that all the reactions under this investigation follow a common mechanism ${ }^{24}$. The Hammett plot is also linear $(\mathrm{r}=0.992, \mathrm{SD}=0.03)$ with $\rho=+1.30$ at $303 \mathrm{~K}$. According to Hammett ${ }^{25}$ reaction with positive $\rho$ values are accelerated by electron withdrawal from benzene ring, whereas those with negative $\rho$ values are retarded by electron withdrawal from benzene ring. In this oxidation reactions, the electron withdrawing group increases the rate and the electron donating group decreases the rate. These observations supporting the positive $\rho$ value obtained from the Hammett plot. 


$$
\begin{aligned}
& 2 \mathrm{Im}^{+} \mathrm{Cr}_{2} \mathrm{O}_{7}^{2-}+\mathrm{H}^{+} \stackrel{\mathrm{K}_{1}}{=} \\
& \text { (IDC) }
\end{aligned}
$$<smiles></smiles>

(PIm)

(B A)<smiles>C=CO</smiles><smiles>CC1CCCC1</smiles>

(HY)

\section{Scheme 1}

Table 3. Second-order rate consents and activation parameters for the oxidation of

\begin{tabular}{|c|c|c|c|c|c|c|c|c|}
\hline \multicolumn{5}{|c|}{$\begin{array}{l}{[\mathrm{BA}]=2.0 \times 10^{-2} \mathrm{~mol} \mathrm{dm}^{-3}} \\
{\left[\mathrm{HClO}_{4}\right]=0.4 \mathrm{~mol} \mathrm{dm}^{-3}}\end{array}$} & \multicolumn{4}{|c|}{$\begin{aligned} {[\mathrm{IDC}] } & =1.2 \times 10^{-3} \mathrm{~mol} \mathrm{dm}^{-3} \\
\mathrm{AcOH}-\mathrm{H}_{2} \mathrm{O} & =50 \%-50 \%(\mathrm{v} / \mathrm{v})\end{aligned}$} \\
\hline Substituents & $\begin{array}{r}\quad 10^{2} \\
298 \mathrm{~K}\end{array}$ & $\begin{array}{c}\mathrm{k}_{2}\left(\mathrm{dm}^{3}\right. \\
303 \mathrm{~K}\end{array}$ & $\begin{array}{l}3 \mathrm{~mol}^{-1} \\
308 \mathrm{~K}\end{array}$ & $\begin{array}{l}\left.\mathrm{s}^{-1}\right) \\
313 \mathrm{~K}\end{array}$ & $\begin{array}{c}\mathrm{E}_{a} \\
\mathrm{~kJ} \mathrm{~mol}^{-1}\end{array}$ & $\begin{array}{c}\Delta \mathrm{H}^{\#} \\
\mathrm{~kJ} \mathrm{~mol}^{-1}\end{array}$ & $\begin{array}{c}-\Delta \mathrm{S}^{\#} \\
\mathrm{~J} \mathrm{~K}^{-1} \mathrm{~mol}^{-1}\end{array}$ & $\begin{array}{c}\Delta \mathrm{G}^{\#} \\
\mathrm{~kJ} \mathrm{~mol}^{-1}\end{array}$ \\
\hline$\overline{p-\mathrm{OCH}_{3}}$ & 0.23 & 0.29 & 0.38 & 0.55 & 44.1 & 42.10 & 154.46 & 88.9 \\
\hline$p-\mathrm{CH}_{3}$ & 0.40 & 0.58 & 0.72 & 0.84 & 38.0 & 35.47 & 171.36 & 87.4 \\
\hline $\mathrm{H}$ & 0.80 & 1.15 & 1.50 & 1.98 & 45.7 & 43.15 & 140.13 & 85.6 \\
\hline$p-\mathrm{Cl}$ & 1.47 & 1.90 & 2.60 & 3.00 & 38.1 & 27.65 & 186.16 & 84.1 \\
\hline$p-\mathrm{CN}$ & 4.83 & 6.20 & 7.00 & 8.40 & 27.7 & 25.12 & 185.65 & 81.4 \\
\hline$p-\mathrm{NO}_{2}$ & 6.00 & 7.50 & 8.80 & 9.60 & 22.9 & 21.88 & 194.61 & 80.9 \\
\hline
\end{tabular}
benzaldehyde and some para-substituted benzaldehydes by IDC. 


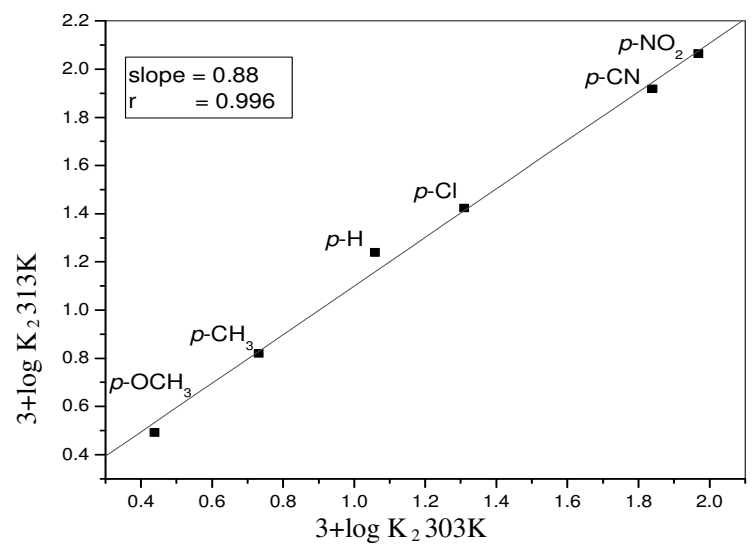

Figure 3. Exner plot between $\log \mathrm{k}_{2}(313 \mathrm{~K})$ versus $\log \mathrm{k}_{2}(303 \mathrm{~K})$.

\section{Conclusions}

The oxidation of benzaldehyde by IDC is an acid catalysed reaction and yields the corresponding benzoic acid as the product. The reaction is first order each in [Substrate], [Oxidant] and $\left[\mathrm{H}^{+}\right]$. The stoichiometry was found to be 3 mol of aldehydes consuming $2 \mathrm{~mol}$ of IDC. The plots of $\log \mathrm{k}_{1}$ versus 1/D were found to be linear, with positive slopes. The negative values of $\Delta \mathrm{S}^{\#}$ provided support for the formation of a rigid activated complex.

\section{References}

1. Wiberg K B, Oxidations in Organic Chemistry, Academic Press, NewYork, 1965.

2. Corey E J and Boger D L, Tetrahedron Lett., 1978, 28, 2461.

3. Narayanan N and Balasubramanium T R, J Chem Res (S)., 1991, 336.

4 Grover A, Varshney S and Banerji K K, Indian J Chem., 1994, 33A, 622.

5. Narayanan N and Balasubramanian T R, Indian J Chem., 1986, 25B, 229.

6. Krishnapillai M and Jameel A A, Indian J Chem., 1992, 31A, 46.

7. Fathimajeyanthi G, Vijayakumar G and Elango K P, J Serb Chem Soc., 2002, 67, 803.

8. Pandurangan A and Murugesan V, Oxidn Commun., 1997, 20, 93.

9. Dhariwal V, Yajurvedi D and Sharma P K, Indian J Chem., 2006, 45A, 1158.

10. Pandurangan A, Murugesan V and Palanisamy M, J Indian Chem Soc., 1995.72, 479.

11. Pandurangan A, Kavitha S and Alphonse I, Indian J Chem., 2005, 44A, 715.

12. Bhattacharjee M N, Chaudhuri M K, Dasgupta H S, Roy N and Khathing D T, Synthesis, 1982, 588.

13. Banerji K K, J Org Chem., 1988, 53, 2154.

14. Banerji K K, J Chem Soc., Perkin Trans 2, 1978, 639.

15. Sekar K G, Oxidn Commun., 2003, 26, 198.

16. Medien H A A, Z Naturforsch., 2003, 58b, 1201.

17. Mathiyalagan N and Sridharan R, Indian J Chem., 2005, 44A, 2044.

18. Agarwal S, Chowdhury and Banerji K K, J Org Chem., 1991, 56, 5111

19. Krishnasamy K, Devanathan D, Dharmaraja J, Trans Met Chem., 2007, 922.

20. Bell R P, Adv Phys Org Chem., 1964, 4, 1.

21. Chaubey G S, Das S, Mahanti M K, Kinetics and Catalysis., 2002, 43, 789.

22. Mohamed Farook N A, J Solution Chem., 36, 2007, 345.

23. Amis E S, Solvent Effects on Reaction Rates and Mechanisms, Academic Press, New York, 1967

24. Srinivasan C and Subramanian P, J Chem Soc., Perkin Trans 2, 1990, 1061.

25. Hammett L P, Physical Organic Chemistry, $1^{\text {st }}$ Edn. McGraw-Hill, New York, 1940. 


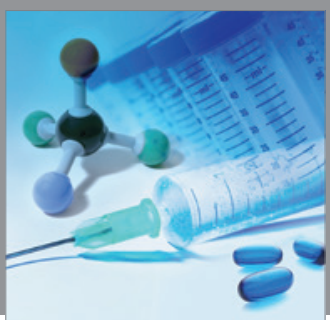

International Journal of

Medicinal Chemistry

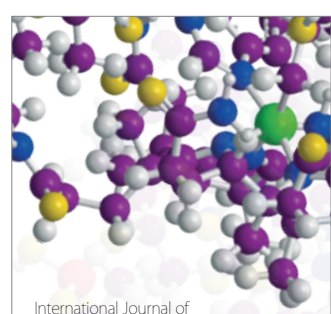

Carbohydrate Chemistry

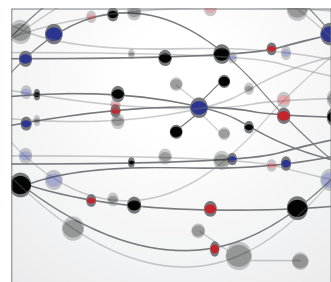

The Scientific World Journal
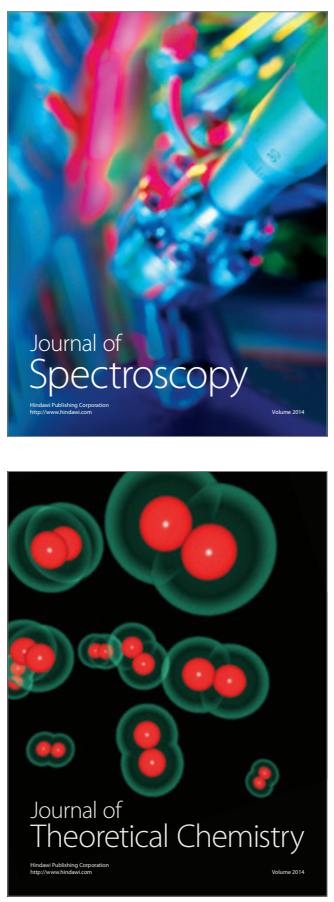
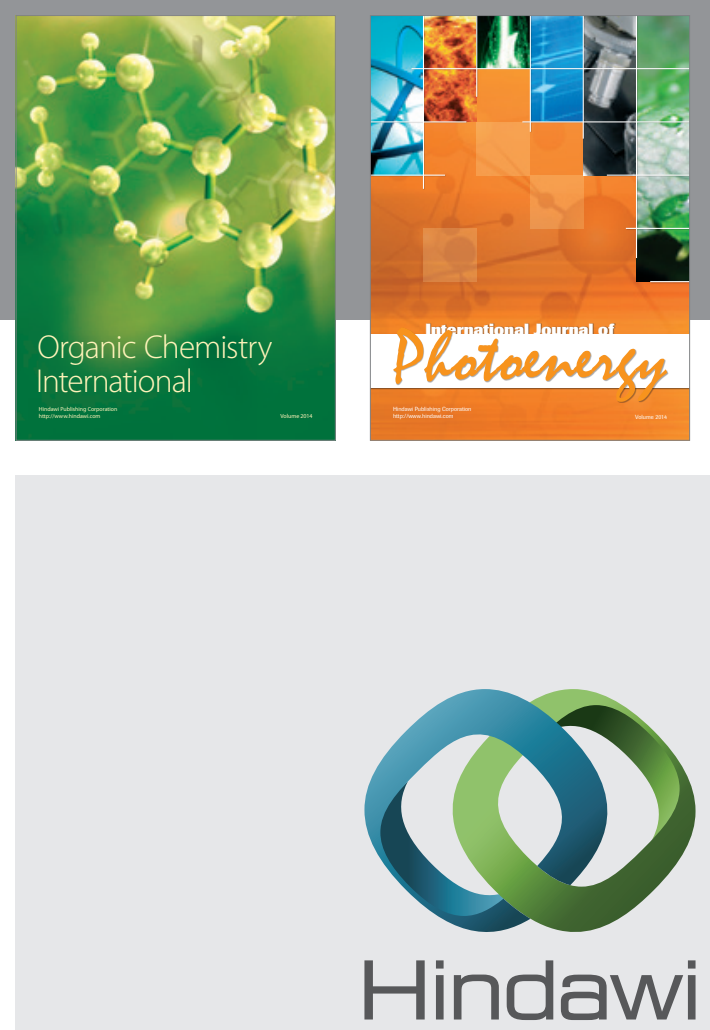

Submit your manuscripts at

http://www.hindawi.com
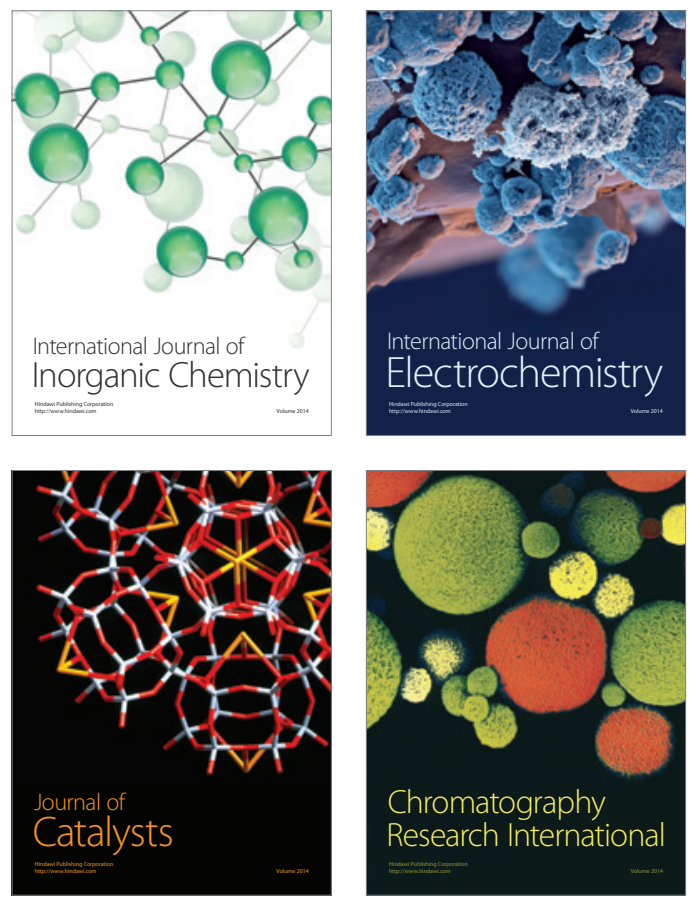
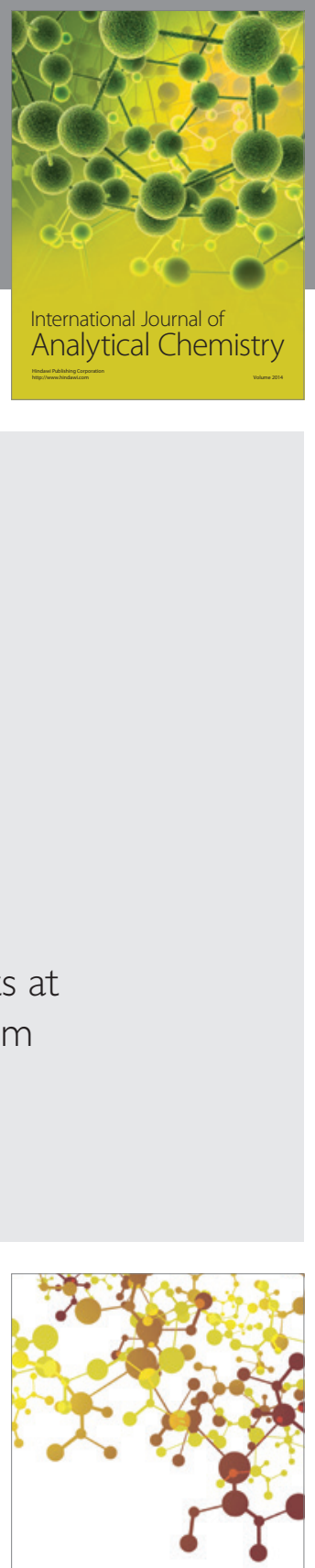

Journal of

Applied Chemistry
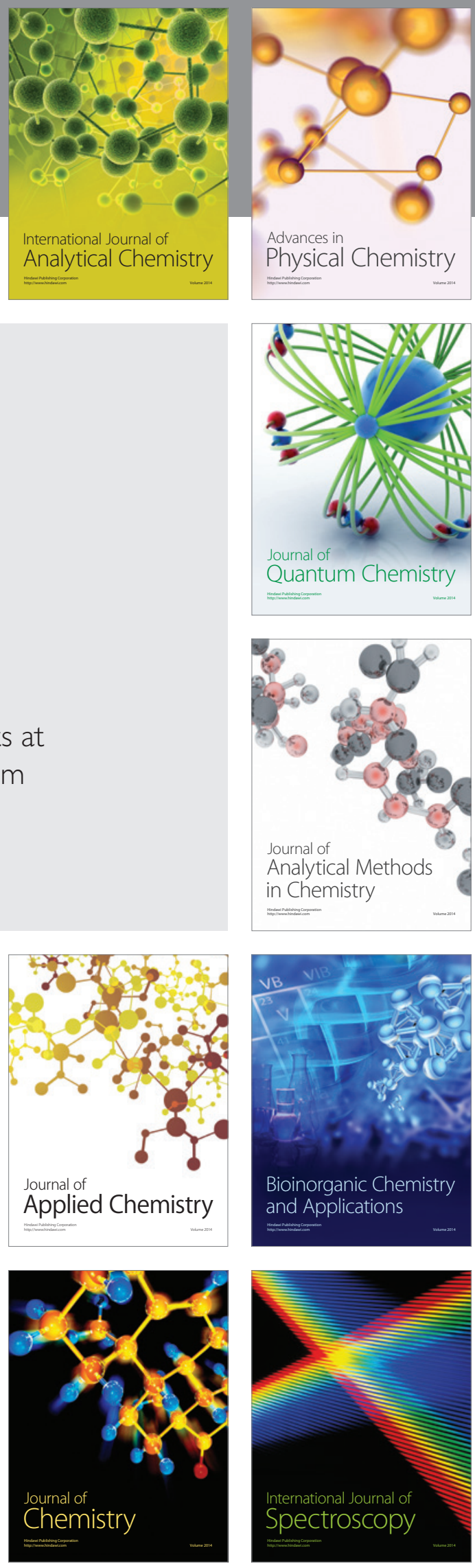